\title{
Decolonising curriculum change and implementation: Voices from Social Studies Zimbabwean Teachers
}

DOI: http://dx.doi.org/10.17159/2223-0386/2021/n25a1

Pfuurai Chimbunde

University of KwaZulu-Natal, Durban, South Africa

chimbundep@gmail.com

Orcid: 0000-0002-3423-2163

\section{Maserole Christina Kgari-Masondo \\ University of KwaZulu-Natal, Durban, South Africa \\ Kgarimasondo@ukzn.ac.za}

Orcid: 0000-0002-1850-6363

\section{Abstract}

In 1980, Zimbabwe inherited a Eurocentric education system from the British colony, aimed at the perpetuation of the subordination and silencing of the African child. When the government of Zimbabwe noticed the infestation of the colonial wound, demonstrated by the irrelevance and in-applicability of the inherited education system, it called for its reconstruction on a new curriculum, which was rolled out in 2015. However, Zimbabwean Social Studies teachers reported intractable inconsistencies in curriculum design and implementation between what is taught in the classroom and what is expected in the society, which they linked to lack of Ubuntu values and a decolonization perspective. Using the Social Studies curriculum as a case and the Ubuntu lens as a conceptual framework, this qualitative study investigates the strategies which can be used to reform the curriculum so that it speaks to the dictates of the Zimbabwean community in which it serves. Data were generated through semi-structured interviews and Focus Group Discussion (FGD) from 12 purposefully sampled Social Studies teachers located in different school settings of Zimbabwe namely the rural, urban, growth points and farm areas. Findings indicated that the 'usable past' anchored in Ubuntu values as part of the decolonization agenda, though not given serious consideration in Zimbabwe, is fundamental to curriculum reform and implementation. Considering the findings, the study recommends the revisiting and extracting from the African past and its values to drive curriculum change to prepare the 
learner to lead an African life in the African continent. The study elucidates the need for a collective psyche in educational change in which curriculum planners practise cordial relations and engage the teachers in curriculum construction to perfect curriculum design and implementation.

Keywords: Curriculum change; Curriculum implementation; Decolonisation; Social Studies; Ubuntu; 'Usable past'. 


\section{Introduction}

In 2017, Zimbabwe introduced an updated curriculum which was believed to address her socio-economic, cultural, and political woes, based on the notion that much of what was inherited in 1980 after political independence was not Zimbabwean, but rather a reflection of Britain in Zimbabwe (Chavhunduka \& Moyo, 2003; Gasva \& Moyo, 2017). Elsewhere in African countries, especially in South Africa, the call for decolonisation of the curriculum had gained momentum since the advent of the Rhodes must Fall campaign by students in universities to address the societal priorities (Le Grande, 2016; McGregor \& Park, 2019; Pillay \& Swanepoel, 2019). Zimbabwe, despite its desire to transform the education system in the spirit of decoloniality, was found to have an education system which had lacked social meaning and relevance for over four decades. When it became evident that the pursuance of colonial education policy and practice inherited in 1980 was not good enough for the country, it was decided that the school curriculum should be revamped. That decision saw the roll out of the Ubuntu driven curriculum in 2017, in which Social Studies was ingrained. The embracing of Ubuntu and its adoption as the guiding philosophy in the education system of Zimbabwe was a move in the right direction, for which several researchers had agitated (Hapanyengwi-Chemhuru \& Makuvaza, 2014; Samkange \& Samkange, 1980; Zvobgo, 1996). It was a demonstration that the African values that have been overwhelmed by colonialism could be restored and renewed; and then be merged into practical and scholarly strands that address the dehumanisation and erosion of African institutions in the construction of knowledge (Zamora, 1997). The application of Ubuntu values in curriculum reform and implementation in African countries in this sense embraced the past knowledge of Africans to shape their curriculum in line with their aspirations and needs.

The paper was motivated by the need to contribute to the current debate surrounding the impact of decolonisation of the curriculum, utilising insights from the voices of some Social Studies teachers who had been reported silent in reforming curriculum ((Apple \& Jungck, 1993; Carl, 2005; Yidana \& Aboagye, 2018). This study is the first of its kind to draw from the teachers' voices, to investigate the ways in which the past can be used in the ongoing decolonisation debate. Against this backdrop, the study sought to establish whether Ubuntu and the people's past can be employed in designing and implementing a curriculum, by investigating their use in the construction and implementation of the Social Studies curriculum. This paper is contributing to arguments on the need to decolonise and indigenise the curriculum and make education relevant to the African people in Zimbabwe. 
This engagement is timely as the Curriculum Framework for Primary and Secondary Education (2015-2022) in Zimbabwe will soon be due for review. The paper therefore intends to contribute ideas to that review process.

\section{Literature review}

A substantial literature search detects an upsurge of interest in the use of "the people's past" to inform present and future practices in all life dimensions (Kgari-Masondo, 2013; Davids, 2018; Lanchenicht, 2018; Van Straaten, Wilschut \& Oostdam, 2018). While Van Straaten et al. (2018) take this further by arguing for the employment of the past to orientate the present and the future in the teaching of History, Lanchenicht (2018) and Kgari-Masondo (2013) present lessons from past land displacements to indicate the significance of the 'usable past'. The strengths of these and other studies lie in their articulation of what they termed 'the usable past' to address various facets of human life by arguing for the reconstruction of an ideal society based on the historical context. While these studies provided discernment on the usefulness of the past, they have paid very little attention to its use in curriculum change and implementation. As such, this paper is an attempt to fill this lacuna by bisecting and connecting the importance of the 'usable past' in curriculum reform, tapping into 12 Zimbabwean teachers' representation of the 2015-2022 curriculum change and implementation. We argue that the 'usable past' is deeply rooted in the Ubuntu values that have been a conduit of African societies. Additionally, African societies' past is associated with the deeply-rooted traditional beliefs and values of Ubuntu, which Africans can harness to guide their educational challenges in various ways towards a bright future.

The literature surveyed reflects Ubuntu as an African philosophy, in which solidarity with one another was cherished through communalism, conformity, compassion, respect, human dignity, participation, and collective unity (Mbigi, 2005; Msila, 2014; Bruyn, 2017). This indicates that the philosophy of Ubuntu is a pre-colonial construct, symbolising communalism and human interdependence that has been in existence in Africa for years. Thus, the Ubuntu philosophy, seen this way, is the 'usable past' from the African societies, which people can refer to reconstruct human knowledge.

The philosophical systems scholars had been using in Africa to study educational change were from a Eurocentric perspective (Gross, 1971; Fullan, 2015). While we acknowledge their potency, contribution, and importance, these theories were developed in the European context and, thus, the lenses were Western-oriented, side-lining the African spring of knowledge. Of late, there is a growing body of literature advocating for the 
adoption of Ubuntu in education (Chimbunde \& Kgari-Masondo, 2020; HapanyengwiChemhuru \& Makuvaza, 2014). This current study complements this literature. We felt a study on curriculum space using the Ubuntu philosophy drawn from the Afrocentric views could contribute to the current debates on decolonising the curriculum.

People can draw insightful lessons from the past of Africans' beliefs and values, such as communalism, participation, survival, solidarity, respect, love, and dignity to direct the progress of society. As posed by Higgs and Van Wyk (2007), the Ubuntu philosophy of education draws from the concerns, experiences, and aspirations of Africans and how they construct knowledge (cited in Letseka, 2016) to decolonise curriculum design and implementation. We argue that the use of Ubuntu philosophy and its related work ethics in educational circles is reconnecting and reviving the 'usable past' in curriculum design and implementation, and thus has a valuable place in the education system (Kgari-Masondo, 2017). Similarly, it is in line with the current global debates on decolonisation of the curriculum.

Decolonisation has gained currency in scholarship of which McGregor \& Park (2019:333) define it as a process that:

"involves confronting the academic mentality that ignores indigenous theorists and scientists and aims at placing indigenous information, resources and research culture on an equal footing with those imposed during the colonial era."

Writers in both the Global South and Global North decolonial inquiry, spanning Indigenous rights, African thought, and movements for reparatory justice, contend that knowledge generated within what is termed a 'colonial matrix of power' has left us with a narrow, patriarchal and contested understanding of Africa and the world (Teasley \& Butler, 2020). This means that, at the epicentre of decolonisation of the curriculum is the idea of returning to the traditions and customs of the olden days, which were defined by respect for people, their culture and knowledge systems when constructing the curriculum. So, by decolonising the curriculum, we are allowing those who were historically marginalised to communicate from their frames of reference (Le Grange, 2016; Kgari-Masondo \& Chimbunde, 2021). As such, it is a shift towards an African identity that questions the Western hegemony in educational space and seeks to construct the curriculum from African values and beliefs thereby showing sensitivity to the history and context of being decolonised. Unlike this study, previous studies (Chimbunde \& Kgari-Masondo, 2020; Hapanyengwi-Chemhuru \& Makuvaza, 2014) overlooked the adoption of the 'usable past' as a point of reference in 
educational reforms. The term 'usable past' is hereunder unpacked and interrogated.

\section{The 'usable past'}

The current study is informed by the 'usable past', which means a coherent record of "events and experiences which compile themselves in such a way as to help people understand where they have been, who they are, where they are now and where they might hope to go and whom they might hope to become" (Kimball, 2015:1). A 'usable past', in this context, means those incidents and experiences which assist us to discern where Zimbabweans are coming from as people of Africa, their current identity, and the aspirations which shape their future identify. However, while the past is useful, not all the past is usable or has potential for usability. In other words, there are certain elements from the past which are undesirable and therefore unusable. Evans (2019) explains that the past is a foreign country and most historical lessons and analogies remain slippery, ambiguous, and uncertain. This suggests that people should not look to the past for perfection. As argued by Kimball (2015), when we look to and uncritically glorify a past, we will meet with either disappointment or blindness. To avoid such disappointments, people must sift out the values that no longer speak to them and retain the ones that do, all the while maintaining their identity and rootedness. As such, people must retain, cultivate, and cherish memories to root themselves in their identity for the present. This is because all people need a past to get from there to here. Evans (2019) argues the past must be usable in the sense of providing cognitive and interpretative skills for probing relationships between possibility and actuality, between experience and expectation, and between singularity and repetition. This suggests that the 'usable past', when critically analysed in curriculum change, can be the key to selfjustification, self-identity, and purposeful action toward the future. The understanding of past events and actions therefore, hinges on the period when these actions took place and their implications for the future.

Thus, the 'usable past' is a decolonising approach which is "a narrative of return" to African values which had been tainted by colonisation. It is a return to something African which gives insights to challenges of Social Studies curriculum reform, tapping insights from African institutions' past ways of life in the community. This tenet of the 'usable past' introspected on what could have been done before curriculum implementation to thwart the possibility of the challenges sprouting. This study is conscious of the next review of the Social Studies curriculum which is due after the year 2022. As such, this article stands as a future source for ideas to be included in the next revision of the Social Studies curriculum in Zimbabwe. 


\section{Theoretical framework}

We couch this study in Ubuntu philosophy which has the impetus to usher in new thinking in curriculum change and implementation. The Ubuntu philosophy is a concept deeply rooted in community life. The perspective is made up of work ethics which constitute what scholarship terms social capital, of which Khoza (2018) describes as networks, shared norms, values, and understandings which enhance teamwork within individuals. This indicates that the Ubuntu philosophy denotes connections among individuals which give rise to social networks and norms of reciprocity and trustworthiness. Ubuntu philosophy is therefore a footing on which a society is not only fortified, but rather, it cements and fastens the people together. The strands that run through Ubuntu are of African origin as remarked by Setiloane (1985), which is a piece of locally-made African knowledge which strives on its virtues that emphasise the relevance of a community through the advancement of shared interests. The patterns of social interrelationships that are ingrained in the Ubuntu philosophy enable people to organise actions to attain the sought-after goals (Msila, 2014). It thus blooms on the premise of reciprocal relations and harmonic effort among blended groups. Seen that way, the social network entrenched in the Ubuntu philosophy is a way of developing a sense of togetherness, tapping ability and endowment, and of entrenching prolific human relationship of reliance and permissiveness to bring extraordinary gains to the community.

While the Ubuntu philosophy has been extensively used in management and peace building discourses (Bruyn, 2017; Khoza, 2018), very few studies, if any, had applied it in curriculum design and implementation. Thus, the theoretical framework that shaped this study is Ubuntu, whose major tenets echo the African thought of communalism, whose focus is to construct the bridge between the policymakers and teachers in curriculum implementation. Ubuntu strives on some components, namely metaphysics, ethics, and epistemology (Mangena, 2018), on which the current paper relies.

Ubuntu ethics refers to the idea of morality and use of terms such as good or bad behaviour, respecting or not respecting, and so forth (Mangena, 2018). Hence, the philosophy of Ubuntu is premised on a common moral position in which the community is the source, author, and custodian of moral fibre or standards. How teachers work when implementing a new curriculum must tally with upright morals such as empathy, respect, honesty, and diligence. Metaphysically, Ubuntu's nature of reality is on "being" in which the idea of being has its fullest expression through participation. Sekou Toure and others had termed this "the communion of persons" whereby "being" is a function of the "us" or "we" 
as opposed to the "I", as found and celebrated in the West (cited in Mangena, 2018). The idea of being is relational and carries a communal character. In this light, whatever must be reformed should reflect the realms of togetherness and cooperation in terms of proposing the ways on how to go about the process of curriculum implementation. Seen that way, the African education system can "build cooperation and competitive strategies based on Ubuntu to permeate challenges" of curriculum change and implementation (Mbigi \& Maree, 2005:75).

Ubuntu epistemology is concerned with the meaning, source, and the nature of the knowledge. Battle (2009:135) submits that African epistemology begins with the community and moves to individuality. It indicates that, the idea of knowledge construction in Africa is vested in the community and not in individuals who make up that community. As such, strategies on meaningful curriculum change and implementation reside with the community of stakeholders, made up of community members such as teachers and experts. This implies that teachers in schools have knowledge of what challenges they could face when implementing a new curriculum, which they can represent through narratives. They are custodians of the implementation matrix because of their experiences; hence, their participation in decision making of the educational change is central to effective implementation of the renovated curriculum. Ubuntu epistemology is experiential as seen and applied in the African proverb from the Shona people, which says "Takabva nako kumhunga hakuna ipwa." (We passed through the millet field, and we know that there are no sweet reeds there), which means the experiences accumulated by teachers are useful in assisting policymakers in reforming and implementing a curriculum implementation, as they know when and where they can meet hurdles. As explicitly argued by Ramose (1999), the African tree of knowledge stems from Ubuntu philosophy, which can be seen as a well -spring which flows within African notions of existence since the epistemology strives on wholeness and oneness (Mangena, 2018). The patterns of social interrelationships that are engrained in the Ubuntu philosophy enable people to coordinate actions to achieve the desired goals (Msila, 2014). Ubuntu thus blooms based on mutual relations and harmonised effort among mixed groups. Seen that way, the social network entrenched in the Ubuntu philosophy is a way of building a sense of belonging, identifying skills and talents, and of establishing productive relationships of trust and tolerance to bring great benefits to the people.

The Ubuntu philosophy was handy as it presented a framework that is indigenous to Africa and her educational challenges. Foreign theories had been employed in the African context, causing a mismatch and leaving some critical issues untapped (Chimuka, 2015; 
Kgari-Masondo, 2017). Bruyn (2017:43) argues that the Afrocentric paradigm affirms that Africans and African topics ought to be studied, analysed, and understood from an African (internal) perspective, based on African philosophical assumptions. This points out that the Ubuntu lens is essential in the study of African phenomena as it approaches such phenomena from "within the culture, history, experience, and perspectives of African people" (Pellerin, 2012:153). Dlomo (1991) explains that Ubuntu is strong because it is an indigenous, purely African, philosophy of life, which is not imported from Eastern or Western Europe. Thus, it is something out of Africa, and therefore has a potential to offer African solutions to the African challenges that teachers face in the education sector. Its strength lies in the fact that it is the 'usable past', which means the traditional values and beliefs drawn from the past of African societies, and has the potential to drive reforms in education in Africa and areas that have the same global history.

\section{Methodology}

The study explored the essence of Ubuntu values in the Zimbabwean Curriculum Framework for Primary and Secondary Education. It sought to establish whether the people's past could be employed in designing and implementing the curriculum. This research, cast as a descriptive and interpretive case study, is embedded in the qualitative paradigm. We made use of the interpretive paradigm in the current study because of its axiom that it is sensitive to human values and that reality is subjective, multiple, and a human construct, unlike the positivist approach that relies on measurements and statistical procedures. Teachers were chosen based on the relevance by picking only "information rich" participants from a population under study (Pandey \& Pandey, 2015:54). We solicited data from 12 purposively selected teachers using semi-structured interviews and Focus Group Discussion (FGD) because this current study was "not interested in the whole 'census' or conducting a broad sweep of everything" (Mason, 2002:65). The six schools were selected on the basis that they mirrored the diverse types of schools found in urban and rural areas and farms in Zimbabwe. The 12 teachers who participated in the study were chosen because they pioneered the implementation of the new Curriculum Framework for Primary and Secondary Education (2015-2022) when it was rolled out in 2017. Additionally, these teachers were trained in Social Studies, and could therefore provide relevant data regarding the tenacity of the study. However, the use of the 12 teachers in the study cannot be viewed to be representing all social studies teachers in Zimbabwe hence, based on such a small sample the credibility of findings and conclusion arising therefrom 
becomes greatly compromised. Thus, the findings cannot be generalised but particularised as endowed in a qualitative approach (Pandey \& Pandey, 2015).

\section{Data analysis and ethical issues}

To abide by ethical issues, we obtained a clearance letter from the ethical committee of the University of KwaZulu-Natal after we sought permission from the permanent secretary of the Ministry of Primary and Secondary Education in Zimbabwe. Armed with these approvals, we sought consent from the Provincial Education Director for Masvingo Province who then directed us to the district school inspectors. Permission was also sought from the heads of schools who then assisted us in identifying the teachers who suited our criterion. The teachers were asked for their participation and showed their acceptance to participate by signing the consent form as advised by De Vos, Strydom, Fouché and Delport (2014). Before the interviews and the FGD, we explained to the teachers the purpose of the study, gave them assurance that the findings were to remain confidential, and that fictitious names were to be used throughout the report which could not be linked to their identities. Permission was also sought to audiotape their narrations and to record the discussion. Data generated from the FGD and semi-structured interviews were recorded as words. They were then transcribed and analysed with emerging patterns being noted and developed into themes. We thus adopted the thematic analysis procedures after transcribing and decoding the narratives.

\section{Findings}

Hereunder, we present findings which had been categorised as themes.

\section{The Ubuntu philosophy and curriculum design: a paper exercise?}

It emerged from semi-structured interviews and FGD that the new Social Studies curriculum was intended to focus on the values of Ubuntu, but this was, in practice, not the case (Interviews R1; S1). R1 narrates that:

"We hear of Ubuntu as a philosophy that drives the new 2015-2022 Zimbabwean curriculum. We expected the employment of the Ubuntu values in both designing and implementing it. However, that was not the case because the participation and 
involvement of all stakeholders was limited. What happened was a selection of a few experts by the policy makers, leaving most teachers in the dark. We were later told to implement the curriculum which was crafted at the government level. This shows that the use of Ubuntu philosophy was a window dressing."

This indicates that the essence of Ubuntu, which is participation by all, was not followed during curriculum design. The approach by the Zimbabwean policymakers was a good representation of a power-coercive approach, because it represented a top-down movement of innovation, which is anti-Ubuntu and did not support or facilitate the participation of all people in implementing what was suggested by the government. In terms of Ubuntu, this top-down style of participation is a violation of respect, teamwork, solidarity, and cooperation. As such, the interviewees (Interviews J1; G1; S2; S1) disagreed with how they were consulted, considering it a breach of their human rights and their right to have a say in their societal activities. Interviewees (S1 and S2) stated that the curriculum was an imposition by the government, and that they had no power to change it despite the fact that they were part of the community. In the words of $S 2$ :

"The curriculum was cascaded from the top to the teachers. We were only told to implement what was crafted by policymakers and the invited experts. The ordinary teachers were not consulted. We could not reject its implementation because that could have been an act of misconduct on our part. We are implementers who do not question or change policy."

This explains why teachers remained silenced by the policymakers.

The teachers interviewed mentioned the issue of Ubuntu as they focused on its ethical principles like love (FGD), care $(\mathrm{S} 2 ; \mathrm{R} 1)$, accommodative $(\mathrm{S} 1 ; \mathrm{C} 1)$, participation $(\mathrm{G} 1$; $\mathrm{J} 1 ; \mathrm{R} 1)$, cooperation ( $\mathrm{G} 1 ; \mathrm{M} 2 ; \mathrm{R} 1)$, respect (M2; M1), and humanisation (J2; S2). This research also discovered that, since the curriculum is grounded in such principles, policymakers and implementers should have followed the ethics engraved in Ubuntu philosophy, encouraging the effective involvement of teachers in curriculum design and the implementation of Social Studies. That was evidenced by the policymakers' movement towards embracing Ubuntu philosophy as their philosophical base of the education system, which was in stark contrast to their negligence of this philosophy during the $1980 \mathrm{~s}$ (Samkange \& Samkange, 1980; Zvobgo, 1996; Nziramasanga, 2018). 


\section{Knowledge from the usable past: Confronting colonialisation}

From the semi-structured interviews and FGD, it was revealed that the content observed in the Social Studies textbooks was added to include issues that were related to governance and global issues, excluding African themes like 'living together'. As put by J2:

"While the topics "Global issues" and "governance" are pertinent given the sociopolitical space, Zimbabwe finds itself in currently, the themes inherent in them reflect Eurocentrism. For example, the Western system of governance are learnt without reference to the African system. I then wonder why they left out a theme like "Living together" which promotes humanity and African values for instance respect for leadership and tolerance as a way to represent the African systems of governance. They brought in Eurocentric themes which are not necessarily helpful in the African way of life. We are potent sources of knowledge for the Social Studies curriculum because of our past experiences. As such, we can be helpful in the development of the curriculum content. The content could be easily implemented by drawing references from our communities and our past. It looks like we are still colonized if our experiences are not taken as part of the social studies content."

This suggests that the policymakers did not identify teachers as a potent source of Social Studies content. They belittled them to be mere implementers of an already crafted policy and failed to acknowledge the experiences of the teachers as sources of relevant and worthwhile knowledge. They did not see the importance of the African themes that make up the African way of life. Revelations from observations show that the Social Studies curriculum was aligned to a Eurocentric view, promoting Western-directed governments. The teachers indicated that the non-Africanisation in the Social Studies content was because they were not involved in the curriculum designing process (Interview $\mathrm{J} 2$ ). This relegates teachers to mere implementers. However, findings show that teachers saw themselves as very good curriculum developers because of the experiences they gained from their community life. It was clear that the development of the Social Studies content lacked in this respect, as represented by the teachers' critique of it as a subject that has directed more effort in Western societies, and been powered by Western thinkers. The nature of themes in the new Social Studies topics, as represented by teachers in the study, reflected bias since they were coloured by a Eurocentric slant. This suggests that curriculum planners overlooked the importance of Ubuntu values, even though they claimed it as the 
guiding philosophy in the Zimbabwean education system (MoPSE, 2015).

\section{Ubuntu values and curriculum implementation}

On curriculum implementation and the nature of relations that the school heads displayed, teachers revealed that the support that was given was tainted with a lack of respect, love, and compassion. In an interview, S1 noted:

"Each time I knocked on the door of our head, I received a cold welcome punctuated with a "what is it again" expression on the face. When I explain the purpose of the visit, the school head usually reminds me of my laziness and then an elaboration that we received the same training and as such was not even aware of how to deal with my problems. That is again followed by a serious lecture on why the school cannot honour my requests because of financial constraints. Their behaviour is likened to that of the then Minister of Primary and Secondary Education who once said: "the new curriculum has now come to stay, shape up or ship out."”

This finding also suggests that Ubuntu values were not used in curriculum implementation. The teacher's sentiment reflects poor relations, and therefore denotes a lack of concern, love, and dignity - which are values central to the concept of Ubuntu. If this view represents a lack of humanness, we argue that the teacher, who is exposed to such poor relations from a leader, is likely to unyoke him/herself from the burden of being part of a team, and rather direct their efforts to other issues that are not linked to the goals and visions of the school curriculum. This neglect from the school head speaks volumes on the lack of importance placed on teamwork in an educational setting, which we believe was due to ignorance or a lack of Ubuntu values, which celebrate unity of purpose.

\section{Discussions of findings}

Drawing on the findings above, the top-down approach which policymakers adopted in disseminating Zimbabwe's updated 2015-2022 curriculum, debunks Ubuntu, in that it does not celebrate participation, consultation, respect of involvement, working together, and cooperation, which are critical strands of the Ubuntu values. Benefiting from the Ubuntu lens, the bottom-up approach is more suitable, as it is anchored in consultative meetings in which ideas are shared in mutual respect and understanding. This style of consultation is part 
of the decolonisation process as it embraces the participation of all that is normally silenced in curriculum change and implementation. Letseka (2016:3) explained that "Ubuntu has a practical dimension and, as such, for a proper interconnection and interdependence to take place, coexistence and cohesion should be the connecting and linking factors in the communal action.” The teachers' non-participation in the curriculum change suggests that the Ubuntu value of interconnectedness, using consultative forums such as seminars, conferences, workshops, and meetings, which are likened to indabas (African indigenous traditional meetings) in the context of Ubuntu philosophy, was not adhered to. The link between the basic principles and vision of the curriculum was not adhered to, which posed a problem because tokenistic involvement occurred instead of allowing teachers to fully participate in curriculum design and construction.

The findings of the study suggest that, while the new curriculum in Zimbabwe was grounded in Ubuntu philosophy, its values, such as respecting the involvement of teachers in curriculum design, were not adhered to. From an Ubuntu lens, participation of all stakeholders at the planning stage helps in the ownership of changes. As advised by Mbigi and Maree (2005:105) "villages function through a process of grass-roots democracy in the form of open discussion forums on key issues that affect the village. These forums are called "indabas" in Zulu, "dare" in Shona or "khotlas" in Tswana." This study infers that if Social Studies curriculum implementation is going to be effective, the policymakers had to create open, shop-floor forums at the grassroots level, as well as inclusive forums throughout the teaching fraternity, to discuss competitive and survival issues in curriculum change and implementation. The cardinal point that is drawn from the Ubuntu lens is that these forums must be inclusive and must have an aspect of open agendas. Hence, there must be space to discuss all critical issues which are to do with education reform and implementation. This means that teacher involvement in curriculum development, as seen from the Ubuntu hallmarks, can result in increased participation, relevance, ownership, and commitment, so that when things deviate from the intended plan, there is less finger-pointing.

It is a finding of this study that teachers were not represented in the construction of the Social Studies content, thereby missing on the decolonisation targets, and damaging the Ubuntu philosophy. As such, new topics, with a European slant, were introduced, and others were modified (Interviews, J2; C2; R1; S2). This confirms reports in several studies (Samkange \& Samkange, 1980; Zvobgo, 1996) which claim that Ubuntu philosophy was neglected by the Zimbabwean government in the post-1980 era in favour of the ideology of scientific socialism. Interest in Ubuntu only re-emerged after the Nziramasanga Commission of 1999 which gave birth to the new Social Studies curriculum and explained why some 
themes in the Social Studies curriculum overlooked African values. We argue that each person has dignity. And that this makes him/her someone to be respected, regardless of their social or professional status, or if they are well known or not (Letseka 2016). Teachers in the study indicated that fidelity to the implementation of the new curriculum could have been facilitated by involving them in drafting the decolonised content of the Social Studies curriculum (Interviews S2). The finding tallies with representation as a social construct, as expounded by Kgari-Masondo (2017), who asserted that Social Studies is located in the activities of the world, reflecting the communities it serves and empowering learners with critical lifelong learning skills. Hence, it is represented as a curriculum that can have outcomes based on common models of society, which could have been achieved by the teachers utilising the knowledge of African values that they gained by practising in their communities. This claim is based on the argument that some teachers fail to recognise the importance of African values, or have an insufficient understanding of them.

Borrowing from Ubuntu epistemology, which strives on oneness and is concerned with the meaning, source, and nature of knowledge, this study argues that the content of Social Studies could have been derived from the community as a whole, to address the realities of the community (Dube \& Jita, 2018). The community members (teachers included) had to contribute to the subject matter of the curriculum since Ubuntu epistemology is experiential as reflected and embedded in the Shona proverb: "Takabva nako kumhunga hakuna ipwa", which means: "we passed through the millet field and we know that there are no sweet reeds there" (Mangena, 2018). The teachers' experiences, accumulated in the progression of their lives and duties, were enough to determine the Social Studies content in the African context. Informed by Ubuntu philosophy, the processes of curriculum change and implementation are deemed ongoing and continual, where teachers make meaningful contributions towards the relevance of the subject by tailoring it to "address lived realities" (Dube \& Jita, 2018:907). In that way, unwanted content materials could have been purged. Consequently, relevant concepts could have been incorporated and more African values could have been added, which was not the case. This reflects a source of impediments to effective curriculum change and implementation, which could have been averted by creating space for educators to contribute their knowledge. As such, teachers should have been afforded respect by including them as participants in the reforms, though they are often seen as curriculum implementers. Teachers, therefore, ought to be treated with respect in curriculum change and implementation. Hence Bekker (2006) argues disrespecting or ill-treating other persons was to be avoided (cited in Letseka 2016). The tokenistic involvement of teachers in curriculum implementation, effected by the Education Ministry 
and policymakers' silent approach, was a sign of disrespect, and, effectively, anti-Ubuntu. We affirm that teachers can be designers of the curriculum because they know the local situation and are familiar with the dynamics in their communities, thus fulfilling Eisner's view that individuals must become the "architects of their own knowledge" (Sanchez, 2010:14).

By virtue of the fact that curriculum change and implementation are premised on the need to transform the nations in the political and socio-economic spheres, the values of Ubuntu, such as community, social interdependence, and individual co-operation, become indispensable and present valuable insights into the nature of consultation and participation, suggesting that the stakeholders must be engaged. Therefore, at any one time, any community is more than the sum of the physical elements of which it is composed. This prompted Khoza (2018) to argue that the community is a cauldron, an interlocking circuit, in which the members, not only human, exist in interdependence on one another. As argued by Van Binsbergen (2001), Ubuntu is that well-knit cluster of ideas, believed to have the power to inspire development in the various Southern African communities as it is believed to possess the management ideologies for the sub-region (cited in Chimuka, 2015). Therefore, in the African context, the enactment and management of curriculum change and implementation should draw lessons from the fountain of values enshrined in Ubuntu. This is so because the Ubuntu values have an important role to play in integrating the various groups in education that have been put asunder by Western models of curriculum innovation and implementation, such as the top - down approach (Pansiri, 2014).

Ubuntu philosophy is rooted in sharing, co-operation, group cohesion, communalism, and communitarianism, which could be articulated in the topic "Living together", a topic which regrettably was purged off. This indicates that decolonisation and use of Ubuntu values in the curriculum reform were used as window dressing when constructing the new curriculum. Such representations from teachers had far reaching implications. It highlighted the fact that teachers were, to some extent, not consulted on the content and nature of the Social Studies curriculum, an oversight which led to a situation whereby learners were exposed to non-African values.

From the study, it emerged that, due to some school heads' failure to nurture good relations in school in schools, teachers experienced a sense of rupture in attachment to the Social Studies curriculum implementation. The heads' poor support to staff was identified as a challenge to effective curriculum implementation during interviews and FGD. These school heads offered minimal professional support, chequered by poor relations of arrogance, disrespect, and lack of love (Interviews J1; S2; FGD). Recent studies conclude 
that this is a problem, because the implementation of programmes and initiatives offer the greatest possibility of success if they are supported intellectually and emotionally by the management (Fullan, 2015; Dube \& Jita, 2018; Oder \& Eisenschmidt, 2018). Surprisingly, this study revealed that school heads were themselves unaware of their responsibility to supervise the implementation, because, due to the fact that they were trained under the same roof and taught the same initiatives as the teachers, their orientation of the new reforms was similar to that of the teachers.

Faced with challenges of disrespectful school heads that are devoid of love and respect, the Ubuntu spring is overflowing with values the school leaders can draw from, for inspiration and guidance on curriculum implementation. One such value is a value-based leadership style which includes all people, from the grassroots level, and encourages the team members to sacrifice for the community's goals first before considering their own values. Values which include creative cooperation, open communication, teamwork, and reciprocal moral obligation are embedded in this value-based leadership (Booysen, 2001 cited in Poovan, du Toit \& Engelbrecht, 2006). Indeed, the leader becomes the glue that holds the team members and their values together, enabling members to coalesce and accomplish tasks collectively rather than putting each other asunder. School heads are at the epicentre of the Social Studies curriculum implementation. Their good relations with their subordinates contribute to the success of curriculum implementation, even though it was revealed in the study that some heads were anti-Ubuntu (Interviews S2; C1; M1). As such, Rahman, Pandian, and Kaur (2018:1122) caution that instead of the arrogant "we-know-what is good for you" attitudes from the school heads, the teachers must be consulted rather than told what to do; they must be respected rather than patronised. Similarly, Mingaine (2013) advises that school heads should be involved and concerned, and should supervise the whole process. Some heads of schools' negative attitudes towards the teachers' perceived lack of skills must be altered for them to embrace the essence of sharing of ideas. As the study by Kgari-Masondo (2015) indicated, if people feel aggrieved, they tend to feel less human and resort to negative behaviour. As such, the elitism and exclusion faced by the teachers made them feel a sense of rupture in their attachment with curriculum change and implementation.

\section{Conclusion}

The study is highly relevant as it is topical and resonates with the current voices on the imperative to decolonise the curriculum in the pursuit of an education delivery system 
which seeks to articulate and address concrete existential needs and the wishes of the peoples in once-colonised spaces in Africa and beyond. Whilst most studies focussed on decolonising the curriculum per se, this paper is commendable for taking another slant, which is of decolonising the change as well as the implementation of the curriculum, with reference to Zimbabwe in general and its Social Studies curriculum in particular. Furthermore, adopting the notion of a 'usable past' as the conceptual framework undergirding the discussion makes this study unique and significant.

The study demonstrated that the salient features of Ubuntu are critical in re-asserting a sense of agency to achieve a step forward towards the decolonisation of curriculum implementation. Thus, it is a decolonising philosophy which is "a narrative of return" to African roots of respect, compassion, participation, love, and humanness. This means, it is a return to something African which gives educational solutions to the challenges of Social Studies curriculum implementation, drawing insights from the African institutions' ways of life in the community. As such, the current study implores policymakers to re-situate and reposition the 'usable past' within the mainstream educational spaces and discourse alongside other world views on an equal footing to make the curriculum relevant.

The study suggests not only that the prevailing Western paradigm on education reforms should be interrogated, but also that other ideas and paradigms rooted in Africa's 'usable past', which embraces the traditional African customs, work ethics, and beliefs, should be harnessed. In and of itself, the study considers and appraises the return to the 'usable past' in curriculum design and implementation to ensure that educational leaders allow participation of the community members and not disregard their cultural aspects, as those values are the crucial 'usable past' (Kgari-Masondo, 2013:90).

The study indicated that the way the curriculum is designed and developed tends not to support teacher engagement, and thus, is not sensitive to the context of the needs of a decolonised country whose objectives in education are to have a relevant education that embraces African humanity and concerns. Intrinsically, it makes a call for embracing the Ubuntu values as a return to the 'usable past', in line with the current decolonisation debates. 


\section{References}

Apple, MW \& Jungck, S 1993. Whose curriculum is this anyway? In Apple, MW (ed.), Official knowledge: Democratic education in a conservative age, 118_- 142.

Bruyn, S 2017. An Afrocentric enquiry on lived experience of Ubuntu among isiZulu — speaking persons from different geographic areas. Unpublished DEd thesis. Durban: University of KwaZulu-Natal.

Carl, A 2005. The "voice of the teacher" in curriculum development: A voice crying in the wilderness? South African Journal of Education, 25(2):223-228.

Chavhunduka, K \& Moyo, C 2003. Practicality of exemplary curriculum implementation material. Harare: UNICEF.

Chimbunde, P \& Kgari-Masondo, CM 2020. Representation of the Zimbabwean 20152022 social studies curriculum: Teachers' perspectives on challenges and "ubuntulising" curriculum change and implementation. Perspectives in Education 38(1):269-282.

Chimuka, TA 2015. "Ubuntu": The itinerary, import and utility of the idea. International Journal of African Society Cultures and Traditions, 2(2):58 - 78.

David, MN 2018. Ideology critique as precolonising Pedagogy: Urban forced removals as a case study. Educational Research for Social Change, 7:16-30.

De Vos, AS, Strydom, H, Fouché, CB, \& Delport, CSL 2014. Research at grassroots for social sciences and human service ( $7^{\text {th }}$ ed). Pretoria, South Africa: Van Schaik.

Dlomo, 0 1991. Strategic advantages that can be obtained from ubuntu. Paper read at Secofsaf Seminar. Midrand, SA.

Dube, B \& Jita, T 2018. Rethinking healthy school relations to facilitate curriculum change in Zimbabwe: A relational leadership approach. Issues in Educational Research, 28(4):901-917.

Evans, M 2019. A usable past: a contemporary approach to history for the Western profession of arms. Defense \& Security Analysis, 35(2):133-146, DOI: $10.1080 / 14751798.2019 .160081$

Fullan, M 2015. The new meaning of educational change ( $5^{\text {th }}$ Ed). New York: Teachers College Press.

Gasva, D \& Moyo, W 2017. Teachers' views regarding the adoption of the new curriculum in Zimbabwe: Fostering quality in education and/or national developmental needs. Scholars Journal of Arts, Humanities and Social Sciences, 5(5):455-462.

Gross, N 1971. Implementing organizational innovation: A sociological analysis of planned education changes. New York: Basic Book Inc. 
Hapanyengwi-Chemhuru, O \& Makuvaza, N 2014. Hunhu: In search of an indigenous philosophy for the Zimbabwean education system. Journal of Indigenous Social Development, 3(1):1-15.

Kgari-Masondo, CM 2013. The usable past and socio-environmental justice: From Lady Selborne to Ga-Rankuwa. New Contree, 66(1):71-96.

Kgari-Masondo, CM 2015. Women as guardians of the environment in the midst of forced removals: From Lady Selborne to Ga-Rankuwa. Alternation, 1(14): 77-105.

Kgari-Masondo, CM 2017. Rethinking the reflective praxis of the name Social Science:

Pedagogical 'mischief' in the Grade 4 to 9 social science curriculum. Yesterday and Today, 18(2):85-107.

Kgari-Masondo, CM \& Chimbunde, P 2021. Progress of an African student during Covid-19 and beyond in higher education: Re-colonisation of decolonisation? Perspectives in Education, 39(1):323-339.

Khoza, RJ 2018. Concepts of Ubuntu and attuned leadership. London: Penguin.

Kimball, A 2015. The meaning of victory in world war two: The Soviet search for a usable past. Available at https://pages.uoregon.edu/kimball/wwwz.htm. Accessed 5 February 2018.

Lanchenicht, S 2018. Learning from Past Displacements? The history of migrations between historical specificity, presentism and fractured continuities. Humanities, 7(36):1-11

Le Grande, L 2016. Decolonising the university curriculum. South African Journal of Higher Education, 30(2):1-12.

Letseka, M 2016. Open Distance Learning (ODL) through the philosophy of Ubuntu. New York: Nova Publishers.

Mangena, F 2018. Hunhu/Ubuntu in the traditional thought of Southern Africa. Internet Encyclopaedia of Philosophy. Available at Accessed 17 May 2018.

Mason, J 2002. Qualitative researching (2nd Ed.). Thousand Oaks, London: Sage.

Mbigi, L, Maree, J 2005. Ubuntu: the spirit of African transformation management. Randburg, SA: Knowledge Resources

McGregor, R \& Park, MS 2019. Towards a deconstructed curriculum: Rethinking higher education in the global north. Journal of Teaching in Higher Education, 24(3):332-345. Mingaine, L 2013. Challenges in the implementation of ICT in public secondary schools in Kenya. International Journal of Social Science and Education, 4(1):224- 238.

MoPSE 2015. Ministry of primary and secondary education ministerial statement: Update on the proposed curriculum framework for primary and secondary education. Harare, Zimbabwe: Parliament of Zimbabwe 
Msila, V 2014. African leadership models in education: leading institutions through Ubuntu. Kamla-Raj 18(3):1105-1114.

Nziramasanga, CT 2018. Curriculum review process in the context of ZIMASSET: Possible linkages with the CIET provisions. Zimbabwe Journal of Educational Research, $30(1): 25-35$.

Oder, T \& Eisenschmidt, E 2018. Teachers' perceptions of school climate as an indicator of their beliefs of effective teaching. Cambridge Journal of Education, 48(1):3-20.

Pandey, P \& Pandey M 2015. Research methodology: Tools and techniques. Romania: Bridge Center.

Pansiri, KO 2014. Managing educational change: A critique of the top-down primary school management development project in Botswana. European Journal of Business and Social Sciences, 2(12):26-37.

Pellerin, M 2012. Benefits of afrocentricity in exploring social phenomena: Understanding afrocentricity as a social science methodology. The Journal of Pan African Studies, 5(4): $149-160$.

Pillay, D \& Swanepoel, E 2019. An exploration of higher education teachers' experience of decolonising the Bachelor of Education honours curriculum at a South African university. Perspectives in Education 36(2):119-131.

Poovan, N, du Toit, MK, \& Engelbrecht, AS 2006. The impact of the social values of Ubuntu on team effectiveness. MA dissertation. North West, South Africa: University of Stellenbosch.

Rahman, MM, Pandian, A, \& Kaur, M 2018. Factors affecting teachers' implementation of Communicative Language Teaching Curriculum in secondary schools in Bangladesh. The Qualitative Report, 23(5):1104-1126.

Ramose, MB 999. African philosophy through Ubuntu. Harare: Mond Books.

Sanchez, F 2010. Interactive classroom strategies and structures for success. San Francisco, CA: Unified School District.

Setiloane, GM 1985. African theology: An introduction. Johannesburg: Skotaville.

Teasley, C \& Butler, A 2020. Intersecting critical pedagogies to counter coloniality. In: SR Steinberg \& B Down (eds). The SAGE handbook of critical pedagogies, 186-204. New York: Sage Publishers

Van Straaten, D, Wilschut, A, Oostdam, R 2018. Exploring pedagogical approaches for connecting the past, the present and the future in history teaching. Historical Encounters: A Journal of Historical Consciousness, Historical cultures, and History Education, 5(2):4667. 
Yidana, MB \& Aboagye, GK 2018. Management of curriculum change: A mechanism for ensuring continuous academic improvement in Ghanaian universities. International Journal for Innovation Education and Research, 6(2):41-60.

Zamora, LP 1997. The usable past: The imagination of history in recent fiction of the Americans. Cambridge: Cambridge University Press.

Zvobgo, RJ 1996. Transforming education: The Zimbabwean experience. Harare: College Press. 